\title{
Human Resources and Logistic Requirements in Problem Based Learning Compared to Traditional Learning
}

\author{
Satish Kumar Deo'.
Department of Clinical Pharmacology,Institute of Medicine,Trivuwan University Teaching Hospital; Kathmandu Nepal.

Problem-based learning (PBL) is a student-centered pedagogy in which students learn about a subject in the context of complex, multifaceted, and realistic problems. Working in groups, students identify what they already know, what they need to know, and how and where to access new information that may lead to resolution of the problem along with discussion of the solution within the group.

Few medical schools in Nepal have already incorporated problem-based learning into their curricula and other medical schools are planning to adopt. However, when PBL is introduced into a curriculum, it has implications for staffing and learning resources and demands a different approach to timetabling, workload, and assessment. So, issues like human resources requirements and logistic requirements need to address specifically from Nepal Medical Council for the assurance quality of medical education which, in turn, has contributed in enhancing the quality of health care services in Nepal.

Hence, this paper is prepared for developing further understanding about major difference between conventional method of Medical education and PBL in relation to human resources requirements and infrastructure. This article ends with some of the important recommendations that could be considered additionally to existing minimum requirements from Nepal Medical Council for the Medical Schools/ Universities in Nepal who are running or planning to implement Problem-based Learning in their curricula.

\section{INTRODUCTION}

In problem based learning (PBL) students use "triggers" from the problem case or scenario to define their own learning objectives. Subsequently they do independent, self directed study before returning to the group to discuss and refine their acquired knowledge. Thus, PBL is not about problem solving per se, but rather it uses appropriate problems to increase knowledge and understanding. The process is clearly defined, and the several variations that exist all follow a similar series of steps.

The first PBL medical curriculum in North America was established at McMaster University in Toronto in 1969. The University of New Mexico was the first to adopt a medical PBL curriculum in the United States, and Mercer University School of Medicine in Georgia was the first U.S. medical school to employ PBL as its only curricular offering. Many interpretations of the basic PBL plan are in use in North American medical schools. Common features include small-group discussions of biomedical problems, a faculty role as facilitator, and the student's relative independence from scheduled lectures.

\section{Human Resources Requirements in PBL}

There are mainly two types of Human resources required in PBL. First is "Facilitators" who is well trained in PBL process and has acquired skills in facilitation and management of group dynamics. Second is "Content expert" or "subject expert" who posses' specialization in their concerned discipline. Subject expert can act as Facilitators only after undergoing proper training is conducted about entire process of PBL. One study reported that it takes between 500-600 hours of Faculty time to provide 130 hours of lecture in traditional medical schools. (1)

It has been found by Barrows \& Tamblyn (1980) in 
NOAJ July-December 2013|Vol 3| Issue 2

their landmark work on PBL that a number of problems are encountered during transition from traditional approach to PBL. Among the problems major ones include need of more staff time and need of additional resources like additional learning materials, books, electronic materials and space (2)

According to Albanese \& Mitchell (1993), Problembased Learning required $22 \%$ more time than the more traditional mode of teaching: a 98-week lecture course required 120 weeks using PBL. When tutors consider the time per week in preparation for teaching problems, in comparison to presenting lectures, they may notice that it takes more time. They found 8.6 hours a week primarily preparing lectures, faculty spent 20.6 hours a week primarily in groups with students. (3)

\section{Logistic requirements in $\mathrm{PBL}$}

A typical PBL tutorial consists of a group of students (usually 8 to 10) and a tutor, who facilitates the session. So there is a minimum need of additional tutorial room with every 10 students. All tutorial room should be well equipped with proper seating arrangements, white board, Over Head Projectors and preferably with computer with internet (Wi Fi) connection. Large cohort students need to access to the same library and computer resource simultaneously and therefore resources required by PBL may put an increased strain on the institution

\section{Recommendations}

Based on above fact finding, Nepal Medical Council believes that below mentioned points should be addressed before incorporating PBL system of education in their curricula.

1. There is greater demand of number of faculties for running PBL system of education. All subject experts should receive mandatory training to understand method of learning when they are appointed as facilitators. Since there is $22 \%$ more time required for mode of teaching and 2.3 times more time preparation traditional methods (8.6 hours a week compared to 20.6 hours per week), Nepal Medical Council feels that number of faculties required should be more than conventional method of teaching learning.

2. There should be provision for sufficient tutorial room proper sitting arrangements. All rooms should be equipped with learning aid like white board, over Head Projectors and computer with Wi Fi connections

3. Since large number of students have to utilize same books at the same time, number of books present in library should be more preferably in the ratio of $1: 2$..

\section{CONCLUSION}

The benefits of PBL are numerous and varied. They range from a more motivated self-directed learner to the acquisition of lifelong learning skills in solving problems and the processes that go with in however, the commonest concern is the higher delivery costs of the PBL curriculum, both financial and in more staff time. The PBL approach is dependent on the functioning of the group, and requires an effective tutor who should be expert not only in subject matter but also well trained to act as a facilitator. So Nepal Medical Council feels above mentioned recommendation should be properly addressed before any institution start PBL system of education in Nepal

\section{REFERENCES}

1. Donner RS, Bickley H. Problem-based learning: an assessment of its feasibility and cost. Hum Path 1990;21(9):881-

2. Barrows, H.S. \& Tamblyn, R.M.. Problem-based Learning. An Approach to Medic Education. New York: Springer. (1980)

3. Albanese, M. and Mitchell, S.. PBL: A review of the literature on its outcomes and Implementation issues. Academic Medicine, (1993)68, 52-81. 